\title{
Experimental study on spalling risk of concrete with 115 120MPa subject to ISO834 Fire
}

\author{
Y. Du ${ }^{\mathrm{a}, \mathrm{b} *}$, Y. Zhu ${ }^{\mathrm{a}}$ and J. Y. R. Liew ${ }^{\mathrm{b}, \mathrm{a}}$ \\ ${ }^{\mathrm{a}}$ College of Civil Engineering, Nanjing Tech University, Nanjing, China \\ ${ }^{b}$ Department of Civil and Environmental Engineering, National University of Singapore, Singapore \\ * e-mail address: yongdu_mail@njtech.edu.cn
}

\begin{abstract}
High strength concrete encased columns are being developed for erecting high-rise buildings as their higher load bearing capacity and smaller cross section size than normal concrete encased column. At ambient temperature, high strength concrete is always mixed with steel fibers to improve its ductility to match the material properties of high strength steel while constructing concrete encased columns. However, for high strength concrete at elevated temperature, spalling usually can be observed due to different thermal properties of various materials mixed such as siliceous aggregate, cement, silica fume, grit and moisture. Most of previous studies present that pore vapor compression induces high strength concrete spalling and propylene fiber can prevent it from spalling. The aim of the present experimental study is to discover the minimum propylene fiber ratio to prevent spalling of 115 120MPa concrete with aggregate and steel fiber. The experimental study carried out on 17 specimens with different water-binder ratio, steel fiber ratio and monofilament propylene fiber ratio exposed to ISO834 fire. The test results that $0.15 \%$ by volume of propylene fibers can prevent $115 / 120 \mathrm{MPa}$ high strength concrete with aggregate from spalling. It is worth noting that propylene fiber mixture ratio of $0.15 \%$ is lower than that of EN 1992-1-2 proposed up to $0.22 \%$. Lower propylene fiber mixture ratio has been soak to improve the workability of 115 120MPa high strength concrete with steel fibers.
\end{abstract}

Keywords: high strength concrete; ISO834 fire; propylene fiber; spalling; steel fiber.

\section{Introduction}

High strength concrete (HSC) with cubic compressive strength of $115 \sim 120 \mathrm{MPa}$ can now be manufactured by most concrete plants due to the availability of a variety of additives such as silica fume and water reducing admixture. In terms of economic advantage, cost studies have shown that HSC can carry the same compression load at least cost than normal strength concrete, and thus the higher material costs for HSC are more than compensated for. In terms of architectural advantage, HSC allows smaller size columns to be used in high-rise construction. This results in more usable space in the buildings [1].

A question may be raised as to what behaviors of the HSC in fire [2]. Recent results of fire tests have shown that there is well-defined difference between the properties of HSC and
NSC at high temperature [3]. However, what is more important about HSC is the occurrence of explosive spalling when HSC is subjected to rapid heating, as in the case of a fire. This failure mechanism was mentioned but not dealt with sufficiently in the previous studies. Experimental studies have shown that explosive spalling of HSC is affected by the following factors: rate of temperature rise, mineralogical composition of the aggregates, thermal induced mechanical stress, reinforcement arrangement, moisture content, and density of the concrete matrix.

HSC is achieved mainly by using a low water-cement $(\mathrm{W} / \mathrm{C})$ ratio and silica fume. Thus, HSC has lower permeability and water content compared with NSC. It has been theorized, and somewhat qualitatively validated by experiments, that the higher susceptibility of HSC which limits the ability of moisture to 
escape from the pore. As heating increases the pore compression also increases. This increase in vapor compression continuous until the internal stresses becomes so large as to cause explosive spalling of the heated concrete. This failure mechanism has been observed on an inconsistent basis by researchers [4]. Often, explosive spalling has occurred to online a fewer HSC specimens from a large group of specimens that were subjected to identical testing conditions. This erratic behavior makes it difficult to predict with certainty when HSC will fail by explosive spalling.

HSC is a rather brittle material. Thus, steel fiber has been used to improve the ductility capacity of the HSC. Meanwhile, polypropylene fiber has been proposed to prevent spalling in case of fire. Then, the higher ratio of fiber can led to twist and reduce workability of the HSC. EN1992-1-2 proposed a value of PP ratio 0.22\% by volume to prevent spalling dependent on the moisture of the concrete for concrete grades $\mathrm{C}$ 55/67 to C 80/95 [5].

The aim of this study is to determine an optimized PP ratio to prevent spalling for cubic strength of $115 \sim 120 \mathrm{MPa}$ of the concrete mix designed by this study. The effect of steel fiber on spalling resistance has also been investigate in this study.

\subsection{Materials and mix design}

P. II Type 52.5 Onoda cement, river sand, granite aggregate with size range of $5 \sim 15 \mathrm{~mm}$, a high-range water reducing admixture, polypropylence (PP) fiber, steel fiber (SF) were used in the production of concrete. The properties of fibers are listed in Table 1. Two types of mix properties of HSC are listed in Table 2. The cubic strength of HSC increased from $116 \mathrm{MPa}$ to $134 \mathrm{MPa}$ while water-binder ratio decreasing from 0.18 to 0.15 . Mixes were casted into $10 \times 10 \times 10 \mathrm{~cm}$ prisms (see Fig. 1) and the specimens were kept in laboratory environment for $24 \mathrm{~h}$. after demoulding, the specimens were labeled and then cured in $98 \%$ humidity at $20{ }^{\circ} \mathrm{C}$ for 28 days. Then, cubic compressive strength under each mixes of HSC have been tested and listed in Table 2 \& 3 respectively. Fifteen specimens of HSC with different water-binder ratio and fiber were produced and listed in Table 3 and specimen size shown in Figs. 2-3.

Table 1. Properties of fibers

\begin{tabular}{cccccc}
\hline Series & $\begin{array}{c}\text { Density } \\
\left(\mathrm{g} / \mathrm{cm}^{3}\right)\end{array}$ & $\begin{array}{c}\text { Melting } \\
\text { point } \\
\left({ }^{\circ} \mathrm{C}\right)\end{array}$ & $\begin{array}{c}\text { Diameter } \\
(\mu \mathrm{m})\end{array}$ & $\begin{array}{c}\text { Length } \\
(\mathrm{mm})\end{array}$ & Shape \\
\hline $\mathrm{PP}$ & 0.92 & 170 & 18 & 16 & Circular \\
$\mathrm{SP}$ & 7.85 & 1535 & 230 & 14 & Circular \\
\hline
\end{tabular}

\section{Experimental study}

Table 2. Mix proportions

\begin{tabular}{rcccccrcc}
\hline Series & W/B & $\begin{array}{c}\text { Cement } \\
\left(\mathrm{Kg} / \mathrm{m}^{3}\right)\end{array}$ & $\begin{array}{c}\text { Silica fume } \\
\left(\mathrm{kg} / \mathrm{m}^{3}\right)\end{array}$ & $\begin{array}{c}\text { water } \\
\left(\mathrm{kg} / \mathrm{m}^{3}\right)\end{array}$ & $\begin{array}{c}\text { Sand } \\
\left(\mathrm{kg} / \mathrm{m}^{3}\right)\end{array}$ & $\begin{array}{c}\text { Coarse aggregate } \\
\left(\mathrm{kg} / \mathrm{m}^{3}\right)\end{array}$ & $\begin{array}{c}\text { Superplasticizer } \\
\left(\mathrm{kg} / \mathrm{m}^{3}\right)\end{array}$ & $\begin{array}{c}\text { Strength }(\mathrm{MPa}) \\
\text { I }\end{array}$ \\
\hline 0.18 & 810 & 90 & 162 & 588 & 882 & 18 & 117 \\
II & 0.15 & 821 & 91 & 137 & 593 & 890 & 18 & 134 \\
\hline
\end{tabular}

Table 3. Details of fire test specimens (Note: the '-_' in Table 3 represent 'none'.)

\begin{tabular}{|c|c|c|c|c|c|c|c|c|}
\hline Specimen & HSC1 & $\mathrm{HSC} 2$ & $\mathrm{HSC} 3$ & HSC4 & HSC5 & HSC6 & HSC7 & HSC8 \\
\hline Mix series & & & I & & & & II & \\
\hline Dimension & \multicolumn{8}{|c|}{$\phi 300 \mathrm{~mm} \times 300 \mathrm{~mm}$} \\
\hline PP (Vol.) \% & 0.10 & 0.22 & 0.15 & 0.15 & - & 0.30 & 0.50 & 0.22 \\
\hline SF (Vol.) \% & - & - & 0.15 & 0.03 & - & 0.15 & 0.15 & - \\
\hline Strength (MPa) & 116.4 & 118.0 & 122.3 & 127.6 & 117.8 & 142.6 & 136.5 & 134.2 \\
\hline Specimen & HSC9 & HSC10 & HSC11 & HSC12 & $\mathrm{HSC} 13$ & HSC14 & $\mathrm{HSC} 15$ & \\
\hline Mix series & \multicolumn{8}{|c|}{ II } \\
\hline Dimension & \multicolumn{4}{|c|}{$\phi 300 \mathrm{~mm} \times 300 \mathrm{~mm}$} & \multicolumn{4}{|c|}{$\phi 100 \mathrm{~mm} \times 200 \mathrm{~mm}$} \\
\hline PP (Vol.) \% & - & 0.10 & 0.13 & 0.15 & 0.10 & 0.13 & 0.15 & \\
\hline SF (Vol.) \% & 1.00 & - & - & - & - & - & - & \\
\hline Strength (MPa) & 134.5 & 122.5 & 133.4 & 130.1 & 122.5 & 133.4 & 130.1 & \\
\hline
\end{tabular}




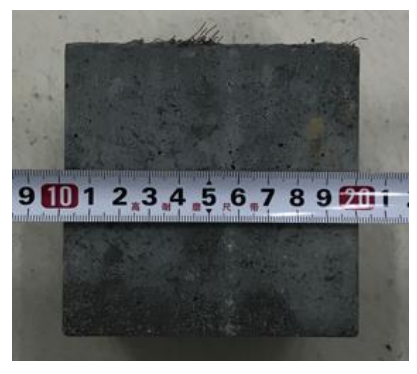

Fig. $1.10 \times 10 \times 10 \mathrm{~cm}$ prism



Fig. 2. $\phi 30 \times 30 \mathrm{~cm}$ cylinder



Fig. 3. $\phi 10 \times 30 \mathrm{~cm}$ cylinder

\subsection{Heating procedure}

A gas furnace that can operate up to $1250^{\circ} \mathrm{C}$ was employed. The heating rate of standard fire curve (i.e. ISO834) has been traced for two hours. A thermal couple was mounted in the core of most specimens to measure the temperature history in the core of HSC specimens as shown in Fig. 4. It is worth noting that the temperature in the core of HSC5 specimen suddenly increased after fire ignition about 50 mins due to the concrete spalling into debris. The temperature in the core of most specimens is up to $200^{\circ} \mathrm{C}$ or so after fire ignition about $2 \mathrm{~h}$.

\subsection{Mercury intrusion porosimetry test}

The characterisation of pore size distribution in the mesoporous and microporous ranges with variety of different concrete. Determination of pore size distribution by mercury intrusion porosimetry. Compression is applied to force mercury into smaller and smaller pores. Measuring the applied compression and the intrusion volume, the pore size distribution can be calculated. As shown in Fig. 5, the mercury intrusion porosimetry reduces with the decrease of compression strength of concrete. Comparison of porosity between the previous studies and two types of mix concrete listed in
Table 2, the specimens holds the same porosity as the previous study with the same strength shown in Fig. 2.

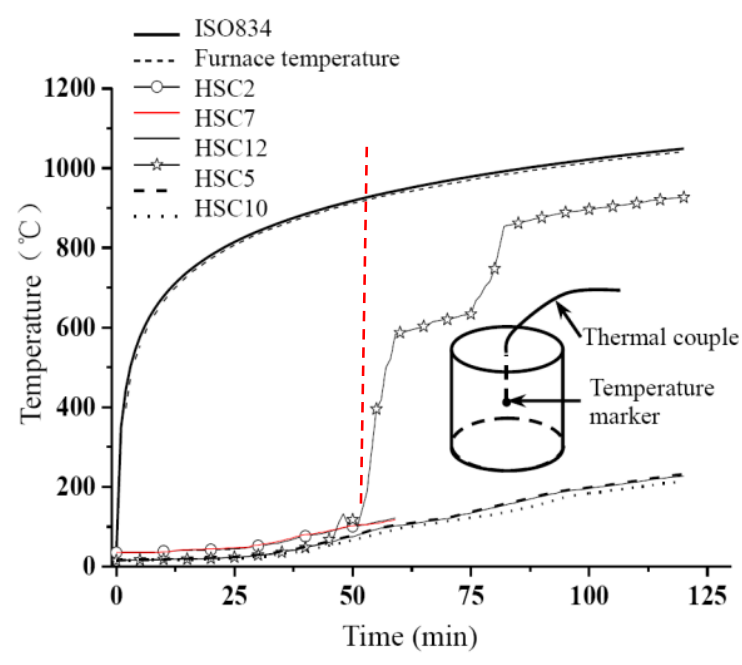

Fig. 4. Temperature history in the core of specimens

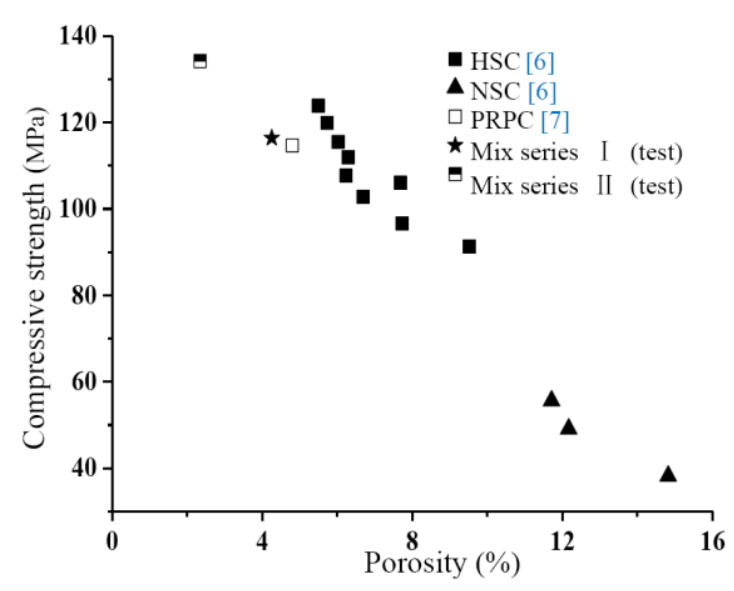

Fig. 5. Comparison of porosity between previous studies and present test

\section{Test results and discussion}

The experimental test results obtained from fire tests and visual observations are discussed in this section. Outer surface of specimens is destroyed, shown in Table 4.

\subsection{Spalling observation}

Shown in Table 4, exposed to ISO834 fire, thoroughly explosive spalling was observed after ignition about $50 \mathrm{mins}$ about $920^{\circ} \mathrm{C}$ for HSC5 specimen without PP fiber \& steel fiber under $0.18 \mathrm{~W} / \mathrm{B}$. As adding $0.10 \%$ PP fiber, HSC1 was formed and observed partial spalling, shown in Fig. 4. If $0.22 \% \mathrm{PP}$ fiber has been mixed to form 
HSC2, no cracking was observed on the outer surface of specimen, shown in Table 4. Regardless of $0.10 \%$ PP fiber cannot absolutely prevent HSC from spalling, PP fiber can provide interconnected channel system while melted above $170^{\circ} \mathrm{C}$.

\subsection{Effect of SF on spalling}

Based on the value of W/B of 0.15 , HSC specimen was produced by mixing with $1.0 \% \mathrm{SF}$, partial spalling was observed as shown in Table 4. This result could be contributed to the effect of steel fiber on spalling. Steel fiber cannot prevent high strength concrete from spalling but can enhance the inter connection of micromaterial.

Table 4. Outer surface of specimens

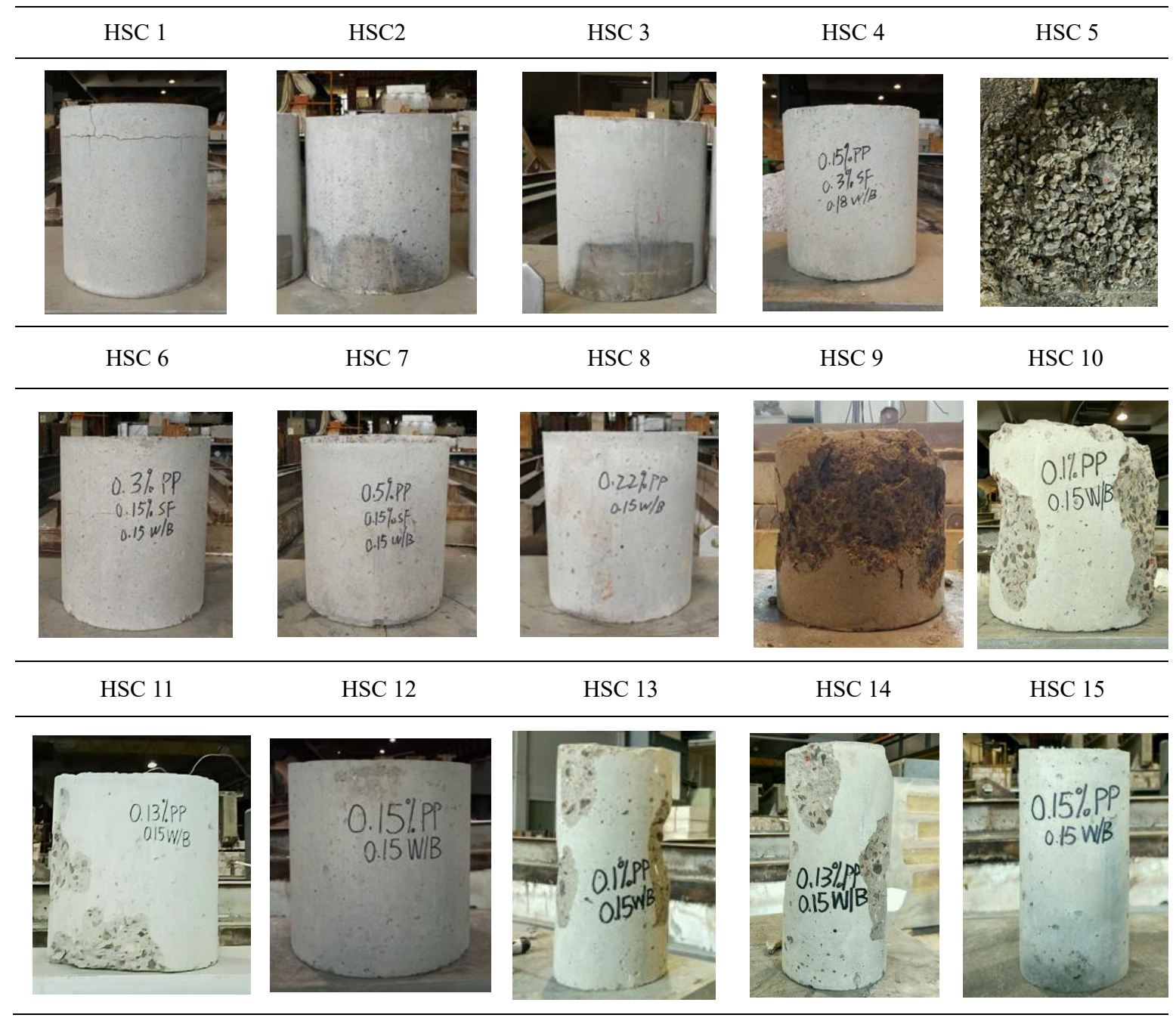

\subsection{Effect of PP fiber on spalling}

In the range of PP fiber volume ration from $0.1 \%$ to $0.5 \%$, outer surface crack or partial spalling of specimens has been shown in Table 4. For W/B of 0.18 , there was no crack observed on the outer surface of the HSC3 and HSC4 specimen with the same PP fiber ration of $0.15 \%$ and different steel fiber mix ratio. For W/B of 0.15 , partial spalling has been observed by heating HSC10 and HSC11 which mixed 0.1 and $0.13 \%$ PP fiber respectively. If update the range of $\mathrm{PP}$ fiber ratio from $0.15 \%$ to $0.30 \%$, there were no cracks on the outer surface of HSC6 HSC9 and HSC12 respectively exposed to ISO834 fire about $2 \mathrm{~h}$. Thus, the minimum PP fiber of $0.15 \%$ has been proposed to prevent $120 \mathrm{MPa}$ concrete from spalling or cracking by this study. 


\subsection{Effect of size of specimen on spalling}

Two sizes of specimen have been produced with the same value of $\mathrm{W} / \mathrm{B} 0.15$. One series of cylindrical specimen is with $300 \mathrm{~mm}$ diameter and $300 \mathrm{~mm}$ height, the others with $100 \mathrm{~mm}$ diameter and $200 \mathrm{~mm}$ height as shown in Table 3 . Two series of specimen are with the same range of PP fiber ratio i.e. $0.10 \sim 0.15 \%$. Shown in Table 4, both of mixture series specimen with PP fiber ratio less than $0.15 \%$ were observed partial spalling, but no crack on the outer surface of specimen with $0.15 \%$ PP fiber exposed to ISO834 fire about $2 \mathrm{~h}$. Thus, if the size of a cylindrical specimen is larger than $\phi 100 \times$ $200 \mathrm{~mm}$, the factor of size will not influence on spalling or cracking for $120 \mathrm{MPa}$ strength concrete under ISO834 fire.

\section{Conclusions}

Behaviours of HSC under high temperature is different from normal concrete due to very dense microstructure. Precaution actions should be taken to prevent the damage when HSC exposed to fire. In this study, effects of PP fiber, steel fiber, water-binder ratio, size of specimen on spalling of HSC with $120 \mathrm{MPa}$ strength have been investigated. A series of conclusions were drawn as below.

- Spalling of $115 \sim 120 \mathrm{MPa}$ HSC is dependent on the ratio of $\mathrm{PP}$ fiber mixed in concrete. Explosive spalling was observed especially in non-fibrous specimen after fire ignition 50 minutes.

- For PP fiber ratio below $0.15 \%$, partial spalling and cracks were observed in $115 \mathrm{MPa}$ and $120 \mathrm{MPa}$ HSC with 0.18 and 0.15 waterbinder ratio respectively. No spalling and cracks was observed if the PP fiber ratio is not below $0.15 \%$. PP fiber ratio of $0.15 \%$ is lower than that of $0.22 \%$ by volume proposed by EN $1992-1-2$, have a remarkable effect on the risk of spalling of series HSC with cubic compressive strength of 115 120MPa.

- Partial spalling was observed in HSC with steel fiber ratio of $1.0 \%$ and no PP fiber. Steel fiber cannot prevent the risk of spalling for HSC, but can improve the inter connection of material.

- Specimen size cannot influence on the PP fiber ratio of $0.15 \%$ to prevent spalling of HSC.

Based on the results of this study it determined that PP fiber ratio of $0.15 \%$ can prevent the risk of spalling for HSC with cubic compressive strength of $115 \sim 120 \mathrm{MPa}$.

\section{Acknowledgements}

The authors gratefully acknowledge the financial support of the International Structural Fire Research Laboratory (ISFRL) in Nanjing Tech University, China.

\section{References}

[1] Mendis P. Design of high-strength concrete members: state-of-the-art. Progress of Structural Engineering Material 2003; 5:1-15.

[2] Akca, AH, Özyurt Zihnioğlu, N. High performance concrete under elevated temperatures. Construction and Building Materials 2013; 44:317-328.

[3] Culfik MS, Ozturan T. Mechanical properties of normal and high strength concrete subjected to high temperatures and using image analysis to detect bond deteriorations. Construction and Building Materials 2010; 24: 1486-1493.

[4] Kodur VKR. Spalling in high strength concrete exposed to fire-concerns cause critical parameters and cures. Proceedings of ASCE Structures Congress. Philadelphia, USA: Advanced Technology in Structural Engineering 2000; 1-8.

[5] EN 1992-1-2, Design of concrete structures. Part 1. 2 General rules - Structural fire design, CEN, 2004.

[6] Poon CS, Azhar S, Anson M, Wong YL. Comparison of the strength and durability performance of normal and high-strength pozzolanic concretes at elevated temperatures. Cement \& Concrete Research. 2001; 31 (9): 1291-1300

[7] Luo BF. Spalling and mechanic properties of high performance silica fume concrete at elevated temperature. $\mathrm{PhD}$. degree thesis, Harbin Technology University, 2014. (in chinese) 